\title{
TSG101, a tumor susceptibility gene, bidirectionally modulates cell invasion through regulating MMP-9 mRNA expression
}

Xu Bin Sai ${ }^{1,2 \dagger}$, Tomohiko Makiyama $^{1 \dagger}$, Hiroshi Sakane ${ }^{1,3}$, Yukimi Horii $^{1}$, Hideyuki Hiraishi ${ }^{2}$ and Hiromichi Shirataki ${ }^{{ }^{*}}$

\begin{abstract}
Background: Tumor susceptibility gene 101 (TSG101) was initially identified in fibroblasts as a tumor suppressor gene but subsequent studies show that TSG101 also functions as a tumor-enhancing gene in some epithelial tumor cells. Although previous studies have unraveled diverse biological functions of TSG101, the precise mechanism by which TSG101 is involved in carcinogenesis and tumor progression in a bidirectional and multifaceted manner remains unclear.

Methods: To reveal the mechanism underlying bidirectional modulation of cell invasion by TSG101, we used RNA interference to examine whether TSG101 depletion bidirectionally modulated matrix metalloproteinase (MMP)-9 expression in different cell types.

Results: TSG101 depletion promoted cell invasion of HT1080 cells but contrarily reduced cell invasion of HeLaS3 cells. In HT1080 cells, TSG101 depletion increased both baseline and phorbol 12-myristate 13-acetate (PMA)-induced MMP-9 secretion through enhancing MMP-9 mRNA expression, but did not affect the expression or activation of MMP-2. In contrast, TSG101 depletion decreased PMA-induced MMP-9 secretion through reducing MMP-9 mRNA expression in HeLaS3 cells. TSG101 depletion had little impact on the signaling pathways required for the activation of transcription of MMP-9 or MMP-9 mRNA stability in either cell line.

Conclusion: TSG101 bidirectionally modulates cell invasion through regulating MMP-9 mRNA expression in different cell types. Our results provide a mechanistic context for the role of TSG101 in cell invasion as a multifaceted gene.
\end{abstract}

Keywords: TSG101, Matrix metalloproteinases, Cell invasion, Tumor suppressor gene, Oncogene

\section{Background}

Tumor susceptibility gene 101 (TSG101) was originally defined as a tumor suppressor gene and its functional inactivation in mouse fibroblasts produces cells with the capacity for colony formation in $0.5 \%$ agar and the ability to form metastatic tumors in athymic nude mice [1]. TSG101 protein contains several unique domains, such as an inactive ubiquitin-conjugating domain, a proline-

\footnotetext{
* Correspondence: hiro-sh@dokkyomed.ac.jpAQ2

${ }^{\dagger}$ Equal contributors

'Department of Molecular and Cell Biology, Graduate School of Medicine, Dokkyo Medical University, 880 Kitakobayashi, Mibu-cho, Tochigi 321-0293, Japan

Full list of author information is available at the end of the article
}

rich region, a coiled-coil domain, and a steadiness box $[1,2]$, implying diverse biological functions for TSG101 in endosomal trafficking [3-5], transcriptional regulation [6-10], and cell proliferation [11]. Recently, TSG101 has received attention in the field of exosome research because of its involvement in multivesicular body formation as a component of the endosomal sorting complex required for transport protein machinery [12-14]. Since inactivation of TSG101 leads to a series of mitosisrelated abnormalities, TSG101 may be involved in genome stability $[15,16]$. Moreover, since inactivation of TSG101 inhibits the endosomal trafficking of activated EGF receptors to the lysosome and thereby results in the 
prolonged induction of downstream signaling cascades, TSG101 may be involved in the negative regulation of receptor tyrosine kinase signaling $[17,18]$. Thus, a series of studies are shedding light on the molecular mechanism by which TSG101 functions as a tumor suppressor gene. However, several recent reports have also demonstrated that TSG101 contrarily functions as a tumor-enhancing gene in some epithelial tumor cells $[19,20]$, suggesting that TSG101 may play divergent roles in carcinogenesis and tumor progression in different cell types.

Matrix metalloproteinases (MMPs) are a family of zinc-dependent proteolytic enzymes that degrade the extracellular matrix (ECM) [21]. This gene family consists of 23 members in human and is subdivided into two types: soluble MMPs and transmembrane-type MMPs. Most soluble MMPs are secreted from the cells as inactive zymogens that are activated on the cell membrane surface. Transmembrane-type MMPs are anchored to the cell membrane where they degrade the ECM and activate other MMPs. MMP activity is tightly regulated at the levels of transcription, activation of proenzymes by post-translational processes, and inhibition by endogenous proteins, i.e., tissue inhibitors of metalloproteinases (TIMP) [22]. However, in tumor invasion, excessive activity of MMPs breaks down the surrounding ECM microstructure, especially the basement membrane barrier, and thereby contributes to the invasion and migration of tumor cells [23-26]. Several studies have shown that among the many MMPs, gelatinases, especially MMP-2 and MMP-9, play a key role in degradation of type IV collagen, a major structural protein for the basement membrane barrier [27, 28]. Furthermore, an increase in expression of MMP-2 and MMP-9 has been reported in many human tumors including neuroblastoma and melanoma [29, 30]. MMP-2 is constitutively expressed in diverse cell types [31, 32]. In contrast, in most human tumors, MMP-9 expression is basally low but upregulated in response to diverse growth factors and cytokines [31-34]. Accumulating evidence suggests that the upregulation of MMP-9 expression contributes to the development of tumor progression such as invasion, metastasis, and angiogenesis [23, 26]. MMP-9 expression is regulated at several levels including gene transcription, mRNA stability, and translation [35-37]. A number of signaling pathways including the PKC, ERK, p38 kinase, JNK, PI3-K/Akt, and NF- $\mathrm{KB}$ signaling pathways are involved in the regulation of MMP-9 expression by various stimuli [38-45].

In this study, we observed that TSG101 depletion bidirectionally modulated cell invasion but not cell migration in different cell types. Among various molecules involved in cell invasion, we suspected that MMPs would be potential targets of TSG101 and used RNA interference (RNAi) to examine whether TSG101 depletion affects the expression of MMP-2 and MMP-9. We found that the regulation of cell invasion by TSG101 through modulating MMP-9 mRNA expression was bidirectional and multifaceted, and our findings unraveled a novel aspect of the functions of TSG101 in cell invasion as a multifaceted gene.

\section{Methods}

\section{Cells, antibodies, and reagents}

HT1080 and U2OS cells were purchased from the ATCC. HeLaS3 cells were a kind gift from Dr. Kishida (Kagoshima University Graduate School of Medical and Dental Sciences). HT1080 cells were grown in a humidified atmosphere of $5 \% \mathrm{CO}_{2}$ and $95 \%$ air in Eagle's minimal essential medium supplemented with $10 \%$ fetal calf serum (FCS) (Invitrogen Corp., Carlsbad, CA, USA), 100 units $/ \mathrm{ml}$ penicillin, and $100 \mathrm{mg} / \mathrm{ml}$ streptomycin at $37^{\circ} \mathrm{C}$. HeLaS3 and U2OS cells were grown in a humidified atmosphere of $5 \% \mathrm{CO}_{2}$ and $95 \%$ air in Dulbecco's modified Eagle's medium supplemented with 10 \% FCS (Invitrogen Corp.), 100 units/ml penicillin, and $100 \mathrm{mg} /$ $\mathrm{ml}$ streptomycin at $37{ }^{\circ} \mathrm{C}$. An anti-glyceraldehyde-3phosphate dehydrogenase (GAPDH) antibody was purchased from MBL (Nagoya, Japan). Anti-MMP-9 and anti-TSG101 antibodies were purchased from Abcam (Cambridge, MA). Anti-Akt, anti-phospho-Akt (Ser473), anti-p38, anti-phospho-p38 (Thr180/Tyr182), anti-JNK, anti-phospho-JNK (Thr183/Tyr185), anti-NF-kB p65, anti-phospho-NF- $\mathrm{kB}$ p65 (Ser536), and anti-I-kB- $\alpha$ antibodies were purchased from Cell Signaling Technology (Danvers, CA). Anti-ERK and anti-phospho-ERK (Thr202/ Ytr204) antibodies were purchased from BD Biosciences (San Jose, CA). PD98059, SB203580, SP600125, and LY294002 were purchased from Cell Signaling Technology. MG132 and bafilomycin A1 were purchased from Calbiochem (San Diego, CA) and Wako Pure Chemicals (Osaka, Japan), respectively.

\section{Transfection}

Cells were transfected with $10 \mathrm{nM}$ small interfering RNA (siRNA) targeting TSG101 or MMP-9 using RNAi max (Invitrogen Corp.) according to the manufacturer's protocol. Negative control, TSG\#1 (GCATGTACGTC TTCTGTCCCGTAAA), TSG\#2 (GATACCCTCCCAA TCCCAGTGGTTA), and MMP-9 (GGAAACCCTGCC AGTTTCCATTCAT) stealth siRNAs were purchased from Invitrogen.

\section{Western blotting}

Cells were washed with cold phosphate buffered saline (PBS) and lysed with a lysis buffer $[50 \mathrm{mM}$ Tris/HCl $\mathrm{pH}$ 7.4, $150 \mathrm{mM} \mathrm{NaCl}, 1 \times$ protease inhibitor cocktails (Roche Applied Science, Basal, Switzerland), $1 \times$ phosphatase inhibitor mixture (Calbiochem), and $1 \%$ NP-40] on ice for $10 \mathrm{~min}$. Cell lysates were clarified by centrifugation 
at $10,000 \times \mathrm{g}$ for $10 \mathrm{~min}$ at $4{ }^{\circ} \mathrm{C}$, and the supernatants were collected for western blotting. Protein lysate concentration was determined using the DC protein assay kit (Bio-Rad, Hercules, CA). The supernatants were separated by SDSPAGE. Western blotting was performed using the ECLPlus immunoblotting detection system (GE Healthcare UK Ltd., Amersham Place, England) in accordance with the manufacturer's instructions. The relative density of each immunoreactive band was quantified using LAS-1000 plus gel documentation system (Fuji Film Co., Fuji, Japan).

\section{Wound-healing assay}

Confluent cells were serum starved for $16 \mathrm{~h}$ prior to being carefully scratched using a $10 \mu$ l pipette tip. The cellular debris was subsequently removed by washing with PBS, and the cells were incubated in fresh serumfree medium containing or not $200 \mathrm{nM}$ phorbol 12myristate 13-acetate (PMA) (Sigma-Aldrich, St. Louis, MO). The cultures were photographed at 0,3 , or $9 \mathrm{~h}$ to monitor the migration of cells into the wounded area, and the width of the wounds is expressed as a percentage of the initial width at zero time.

\section{Invasion assay}

At 48 and 24 h post-transfection, HT1080 and HeLaS3 cells, respectively, were trypsinized to detach cells from the culture dish, resuspended in medium containing $10 \%$ FCS, washed twice with serum-free medium, and resuspended in serum-free medium containing $0.1 \%$ bovine serum albumin (BSA). Invasion assays were then performed using BioCoat Matrigel Invasion Chambers (Corning Life Sciences, Tewksbury, MA) according to the manufacturer's instructions. Briefly, cells $\left(2.5 \times 10^{4}\right.$ cells) suspended in $0.5 \mathrm{ml}$ of serum-free medium containing $0.1 \%$ BSA were added to the upper chamber of Matrigel-coated filter inserts, and $0.75 \mathrm{ml}$ of fresh medium containing $10 \%$ FCS was added to the bottom well as a chemoattractant. The chambers were then incubated for 18 or $72 \mathrm{~h}$. In assays using HeLaS3 cells, the cells in the upper chamber were treated with $200 \mathrm{nM}$ PMA during the assay. After incubation, migrated cells on the underside of the filter were fixed and stained with $20 \%$ (vol/vol) methanol containing $0.1 \%$ (wt/vol) crystal violet powder for $5 \mathrm{~min}$ at room temperature. After extensive washing in PBS, the filters were photographed to count the number of migrated cells on the underside in 30 randomly selected fields.

\section{Gelatin zymography}

At $32 \mathrm{~h}$ post-transfection, cells were serum starved for $16 \mathrm{~h}$ prior to being incubated in fresh serum-free medium containing the indicated reagents for further 7 or $24 \mathrm{~h}$. To measure MMP activities in conditioned media, conditioned media were collected, cleared by centrifugation, normalized to cell number, mixed with non-reducing Laemmli's sample buffer, and subjected to electrophoresis in a $10 \%$ SDS-PAGE gel containing $0.1 \%$ (wt/vol) gelatin. To measure MMP activities in cells, cells were washed with cold PBS twice and lysed in a lysis buffer [50 mM Tris/ $\mathrm{HCl} \mathrm{pH} 7.4,150 \mathrm{mM} \mathrm{NaCl}$, $1 \times$ protease inhibitor cocktails (Roche Applied Science), $1 \times$ phosphatase inhibitor mixture (Calbiochem), and $1 \% \mathrm{NP}-40$ ] on ice for $10 \mathrm{~min}$. Cell lysates were clarified by centrifugation at $10,000 \times \mathrm{g}$ for $10 \mathrm{~min}$ at $4{ }^{\circ} \mathrm{C}$ and the supernatant was collected. Protein lysate concentration was determined using the DC protein assay kit (Bio-Rad). The collected supernatant was mixed with non-reducing Laemmli's sample buffer, followed by electrophoresis in a $10 \%$ SDS-PAGE gel containing $0.1 \%$ (wt/vol) gelatin. After electrophoresis, the gels were incubated in a renaturing buffer (2.5\% Triton X-100) with gentle agitation for $1 \mathrm{~h}$ at $22{ }^{\circ} \mathrm{C}$, washed with distilled water three times, and incubated in a developing buffer (50 mM Tris/ $\mathrm{HCl} \mathrm{pH} \mathrm{7.4,} 150 \mathrm{mM} \mathrm{NaCl}$, and $10 \mathrm{mM}$ $\mathrm{CaCl}_{2}$ ) for $24 \mathrm{~h}$ at $37{ }^{\circ} \mathrm{C}$ to allow digestion of the gelatin. Finally, the gels were stained with Coomassie brilliant blue and destained in $45 \%$ (vol/vol) methanol and $1 \%$ (vol/vol) acetic acid to remove excess dye. The relative density of each gelatinolytic band was quantified using LAS-1000 plus gel documentation system (Fuji Film Co.).

\section{Reverse transcription (RT)-PCR}

Total cellular RNA was isolated from cells using NucleoSpin RNA II (Takara, Shiga, Japan) according to the manufacturer's instructions. Quantitative RT-PCR was performed using a light cycler nano (Roche Applied Science). Forward and reverse primers were as follows: human MMP-2, CCCCAAAACGGACAAAGAG and C TTCAGCACAAACAGGTTGC; human MMP-9, GAA CCAATCTCACCGACAGG and GCCACCCGAGTGT AACCATA; human MMP-14, GCCTTGGACTGTCAG GAATG and AGGGGTCACTGGAATGCTC; human TIMP-1, CTGTTGTTGCTGTGGCTGAT and AACT TGGCCCTGATGACG; human TIMP-2, GAAGAGCC TGAACCACAGGT and CGGGGAGGAGATGTAGC AC; human GAPDH; CCTGTTCGACAGTCAGCCG and CGACCAAATCCGTTGACTCG; and human $18 \mathrm{~S}$ rRNA; GCAATTATTCCCCATGAACG and GGGA CTTAATCAACGCAAGC.

\section{Analysis of mRNA turnover}

HT1080 cells were switched to fresh serum-free medium containing $1 \mu \mathrm{g} / \mathrm{ml}$ actinomycin D (Sigma-Aldrich) to inhibit transcription at $48 \mathrm{~h}$ post-transfection. HeLaS3 cells were pre-treated with $200 \mathrm{nM}$ PMA for $24 \mathrm{~h}$ to promote accumulation of MMP-9 mRNA at $24 \mathrm{~h}$ posttransfection and subsequently switched to fresh serum- 
free medium containing $1 \mu \mathrm{g} / \mathrm{ml}$ actinomycin $\mathrm{D}$ to inhibit transcription. Samples were collected starting 30 min after actinomycin D treatment and at the indicated periods of time. Samples were assayed for MMP-9 mRNA and 18S rRNA mRNA levels by RT-PCR.

\section{MTT assay}

Cells were seeded into a 96-well plate at a density of $2 \times$ $10^{3}$ cells/well in triplicates. At 24, 48, and $72 \mathrm{~h}$ after transfection, $10 \mu \mathrm{l}$ of MTT solution (Dojindo, Kumamoto, Japan) was added into each well. After incubation at $37{ }^{\circ} \mathrm{C}$ for $2 \mathrm{~h}$, the OD at $450 \mathrm{~nm}$ was analyzed on a plate reader.

\section{Statistical analysis}

Each experiment was independently repeated at least three times. The student's $t$-test was used to determine the statistical significance of the value differences between experimental and control groups. Values of $p$ less than 0.05 were considered significant.

\section{Results}

TSG101 depletion promotes cell invasion of HT1080 cells To explore the roles of TSG101 as a tumor susceptibility gene, we used RNAi to examine whether TSG101 is involved in tumor cell biological behaviors such as migration and invasion in HT1080 fibrosarcoma cells. Western blot analysis confirmed that targeted knockdown of TSG101 led to decreased levels of TSG101 expression (Fig. 1a). First, we examined the effect of TSG101 depletion on cell migration using a wound healing assay and found that depletion of TSG101 using TSG\#1 or TSG\#2 siRNA duplexes had no impact on cell migration (Fig. 1b, c). Next, we examined the effect of TSG101 depletion on cell invasion using a Transwell invasion assay. Depletion of TSG101 using TSG\#1 or TSG\#2 siRNA duplexes led to increased numbers of migrated cells on the underside of the filter (Fig. 1d, e), suggesting that TSG101 is involved in cell invasion of HT1080 cells.

\section{TSG101 depletion leads to increased levels of MMP-9 expression in HT1080 cells}

Gelatinases such as MMP-2 and MMP-9 play a crucial role in tumor cell aggressiveness such as invasion and metastasis [27-30]. We first used gelatin zymography to examine whether TSG101 is involved in secretion and expression of these MMPs in HT1080 cells. Depletion of TSG101 using TSG\#1 or TSG\#2 siRNA duplexes led to significantly increased levels of baseline MMP-9 secretion but did not impact baseline MMP-2 secretion (Fig. 2a). Stimulation of HT1080 cells by PMA induces enhanced MMP-9 secretion and MMP-2 activation $[39,41]$. Depletion of TSG101 using TSG\#1 or TSG\#2 siRNA also led to significantly increased levels of PMA- induced MMP-9 secretion, but did not affect PMAinduced MMP-2 activation (Fig. 2a). Moreover, depletion of TSG101 using TSG\#1 or TSG\#2 siRNA duplexes led to significantly increased levels of MMP-9 expression but not MMP-2 expression in cells regardless of treatment with PMA (Fig. 2b). To explore whether TSG101 depletion leads to increased levels of MMP-9 protein in cells, we next performed western blotting experiments. Depletion of TSG101 using TSG\#1 or TSG\#2 siRNA duplexes led to significantly increased levels of MMP-9 protein at least in PMA-treated cells (Fig. 2c). Together, these results indicate that TSG101 depletion leads to increased MMP-9 protein levels and thereby enhances MMP-9 secretion in HT1080 cells.

\section{TSG101 depletion does not affect MMP-9 degradation in HT1080 cells}

At least two possibilities could explain the increased levels of MMP-9 expression in TSG101-depleted cells: one is inhibition of MMP-9 degradation, and the other is enhancement of MMP-9 production. We first examined whether inhibition of proteasomal or lysosomal degradation leads to increased levels of secretion and expression of MMP-9 in HT1080 cells. Treatment with proteasome inhibitor MG132 or lysosome inhibitor bafilomycin A1 did not enhance MMP-9 secretion in control cells to the levels seen in TSG101-depleted cells regardless of treatment with PMA (Additional file 1: Figure S1A). Moreover, treatment with these inhibitors did not increase MMP-9 expression in control cells to the levels seen in TSG101-depleted cells regardless of treatment with PMA (Additional file 1: Figure S1B). The precise reason why bafilomycin A1 inhibited MMP-9 secretion is not known. However, since the NF- $\mathrm{BB}$ signaling pathway is strongly involved in activation of MMP-9 mRNA transcripts in HT1080 cells $[43,46]$ and since the proteasomal degradation of $\mathrm{I} \kappa-\mathrm{B}$ required for the activation of the NF- $\mathrm{KB}$ signaling pathway is inhibited by MG132 [47], it is likely that MG132 inhibits the NF- $\mathrm{B}$ signaling pathway and thereby inhibits MMP-9 expression, especially PMAinduced MMP-9 expression, in both control and TSG101depleted cells. These results support the possibility that TSG101 depletion enhances MMP-9 production.

\section{TSG101 depletion enhances MMP-9 mRNA expression in HT1080 cells}

MMP-9 production is regulated at the levels of gene transcription, mRNA stability, and translation [35-37]. We used RT-PCR to examine whether TSG101 depletion affects MMP-9 mRNA levels in HT1080 cells. Upon treatment with PMA, levels of MMP-9, MMP-9 inhibitor TIMP-1, and MMP-2 activator MMP-14 mRNAs were increased but those of MMP-2 and MMP-2 inhibitor TIMP-2 mRNAs were slightly decreased (Fig. 3a). 


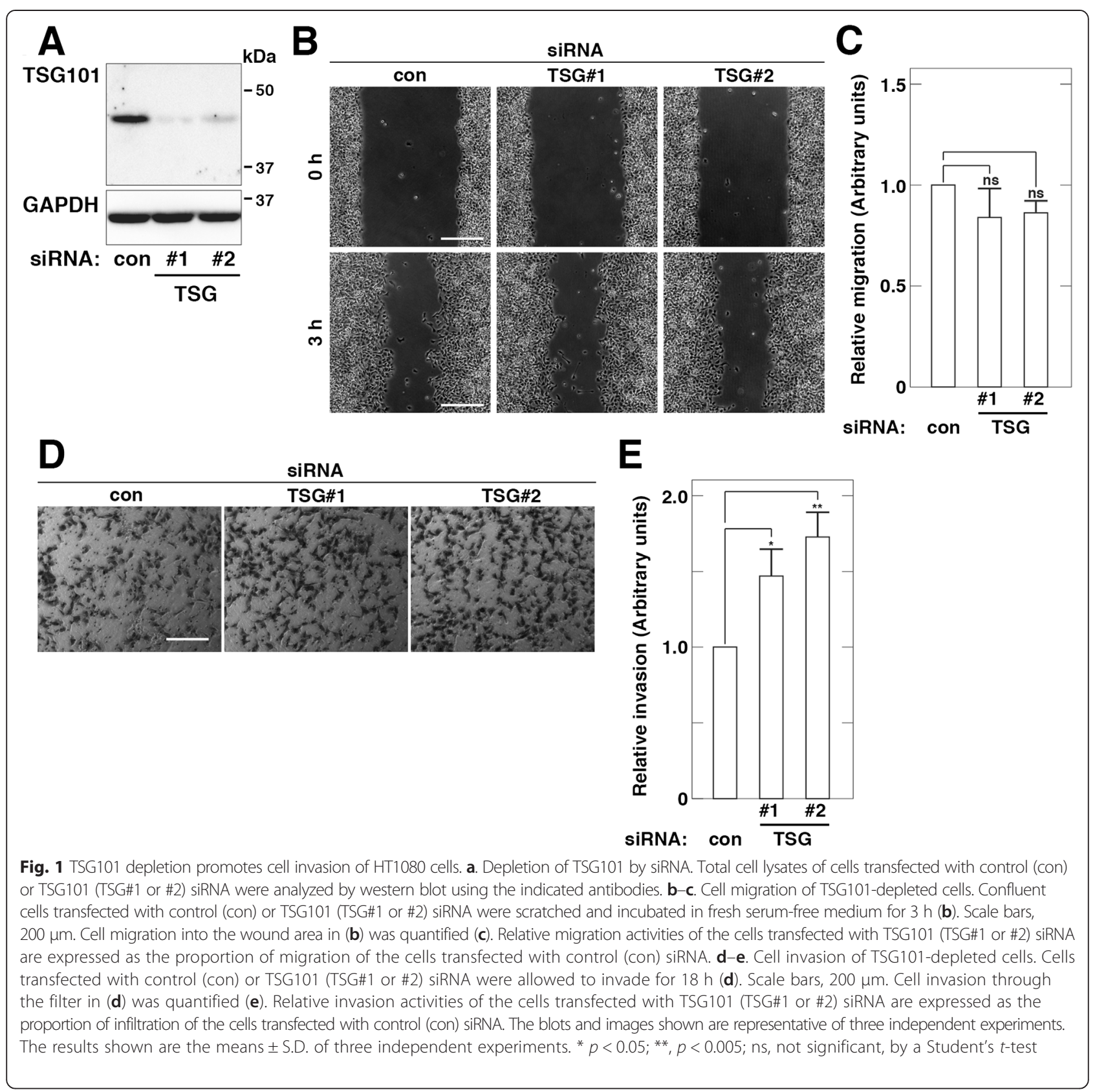

Depletion of TSG101 using TSG\#1or TSG\#2 siRNA duplexes led to significantly increased levels of MMP-9 mRNA but had little impact on mRNA levels of any other examined molecules regardless of treatment with PMA (Fig. 3b). Depletion of TSG101 using TSG\#1 siRNA duplexes led to more increased levels of MMP-9 mRNA than that using TSG\#2 siRNA duplexes, consistent with the results in Fig. 2 showing that depletion of TSG101 using TSG101\#1 siRNA duplexes led to more increased levels of secretion and expression of MMP-9 than that using TSG101\#2 siRNA duplexes. These results demonstrate that TSG101 depletion specifically leads to significantly increased levels of MMP-9 mRNA in HT1080 cells.

TSG101 depletion does not enhance the activities of the signaling pathways required for MMP-9 secretion in HT1080 cells

Stimulation of tumor cells by PMA has been reported to lead to increased levels of MMP-9 secretion through activating several signaling pathways [39, 41, 42], raising the possibility that TSG101 depletion leads to increased levels of MMP-9 secretion through amplifying these signaling pathways. To evaluate this possibility, we first 

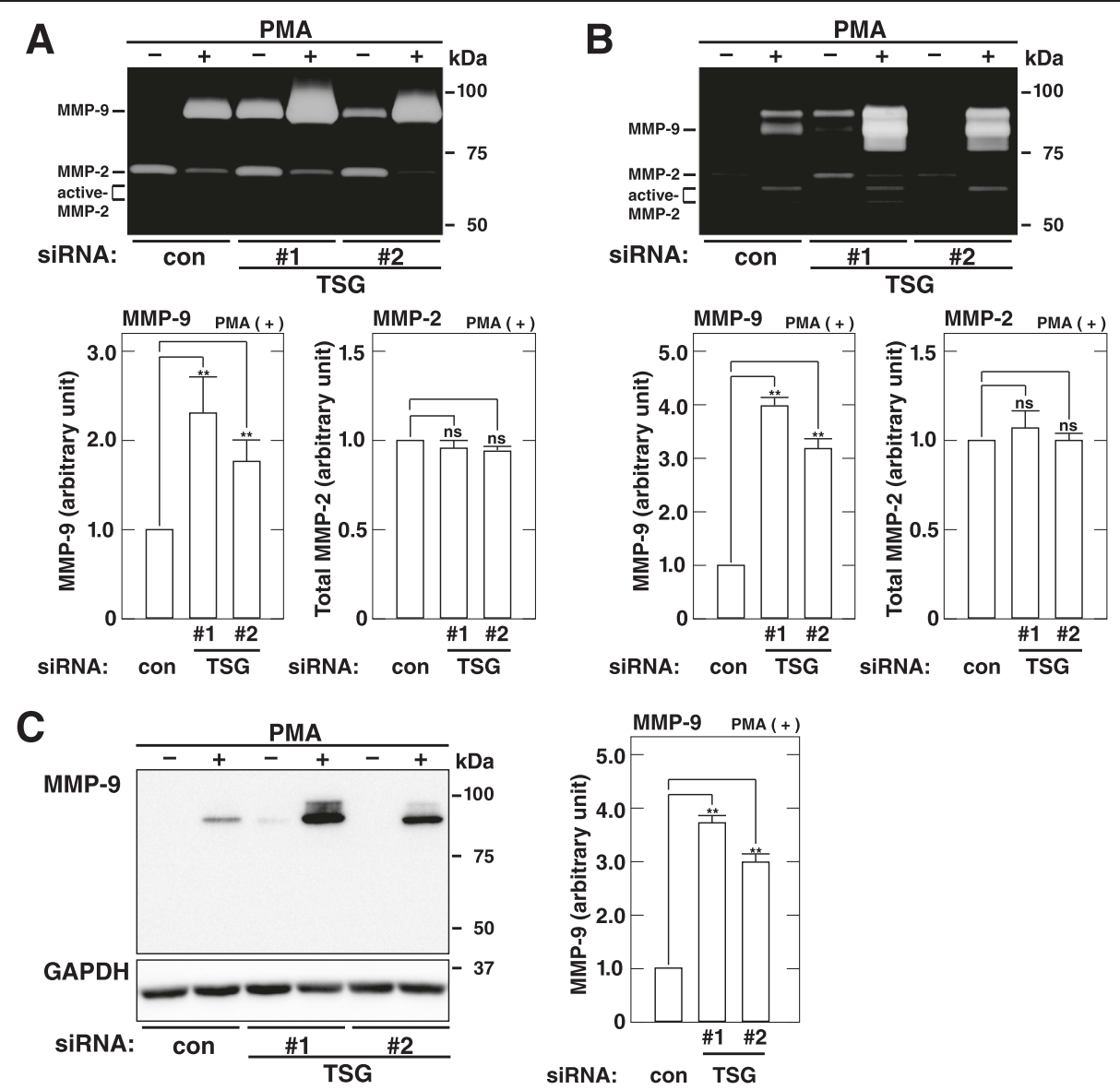

Fig. 2 TSG101 depletion leads to increased secretion and expression of MMP-9 in HT1080 cells. a. MMP-9 secretion in TSG101-depleted cells. b-c. MMP-9 expression in TSG101-depleted cells. Cells transfected with control (con) or TSG101 (TSG\#1 or \#2) siRNA were incubated in fresh serum-free medium containing or not 200 nM PMA for 7 h. MMPs in conditioned media (a, top) and cell lysates (b, top) were measured using gelatin zymography. The amounts of total MMP-2 (MMP-2 + active-MMP-2) and MMP-9 in the conditioned media (a, bottom) and cell lysates (b, bottom) of PMA-treated cells were quantified and are expressed as arbitrary units. The amount of each MMP in the conditioned media and cell lysates of the cells transfected with control (con) siRNA is individually set to 1.0. Cell lysates were analyzed by western blot using the indicated antibodies (c, left). The amount of MMP-9 in PMA-treated cells was quantified and is expressed as arbitrary units (c, right). The amount of MMP-9 in the cells transfected with control (con) siRNA is set to 1.0. The blots and gels shown are representative of three independent experiments. The results shown are the means \pm S.D. of three independent experiments. ${ }^{*}, p<0.005$; ns, not significant, by a Student's t-test

used gelatin zymography to examine the effect of TSG101 depletion on MMP-9 secretion in the presence or absence of chemical inhibitors of these signaling pathways in HT1080 cells. Treatment with the ERK inhibitor PD98095, p38 kinase inhibitor SB203580, JNK inhibitor SP600125, or PI3-K/Akt inhibitor LY294002 significantly reduced PMA-induced MMP-9 secretion in both control and TSG101-depleted cells, but did not decrease PMAinduced MMP-9 secretion in TSG101-depleted cells to the levels seen in control cells (Fig. 4a). Moreover, none of these inhibitors eliminated the increase in baseline MMP-9 secretion in TSG101-depleted cells (Fig. 4b). Taken together with the results shown in Additional file 1: Figure S1, these results demonstrate that the ERK, p38 kinase, JNK, PI3-K/Akt, and NF-kB signaling pathways are involved in PMA-induced MMP-9 secretion in HT1080 cells and suggest that TSG101 depletion does not enhance any of these signaling pathways required for PMA-induced MMP-9 secretion in HT1080 cells. To confirm this, we next performed western blotting experiments with phospho-specific antibodies. TSG101 depletion did not increase but instead slightly reduced activations of the ERK, p38 kinase, PI3-K/Akt, JNK, and NF-KB signaling pathways (Fig. 4c). Although the precise reason why TSG101 depletion reduced activation of these signaling pathways is not known, it is possible that these signaling pathways may be suppressed in a compensatory manner. Together, these results demonstrate that TSG101 depletion does not enhance MMP-9 secretion at least through amplifying 


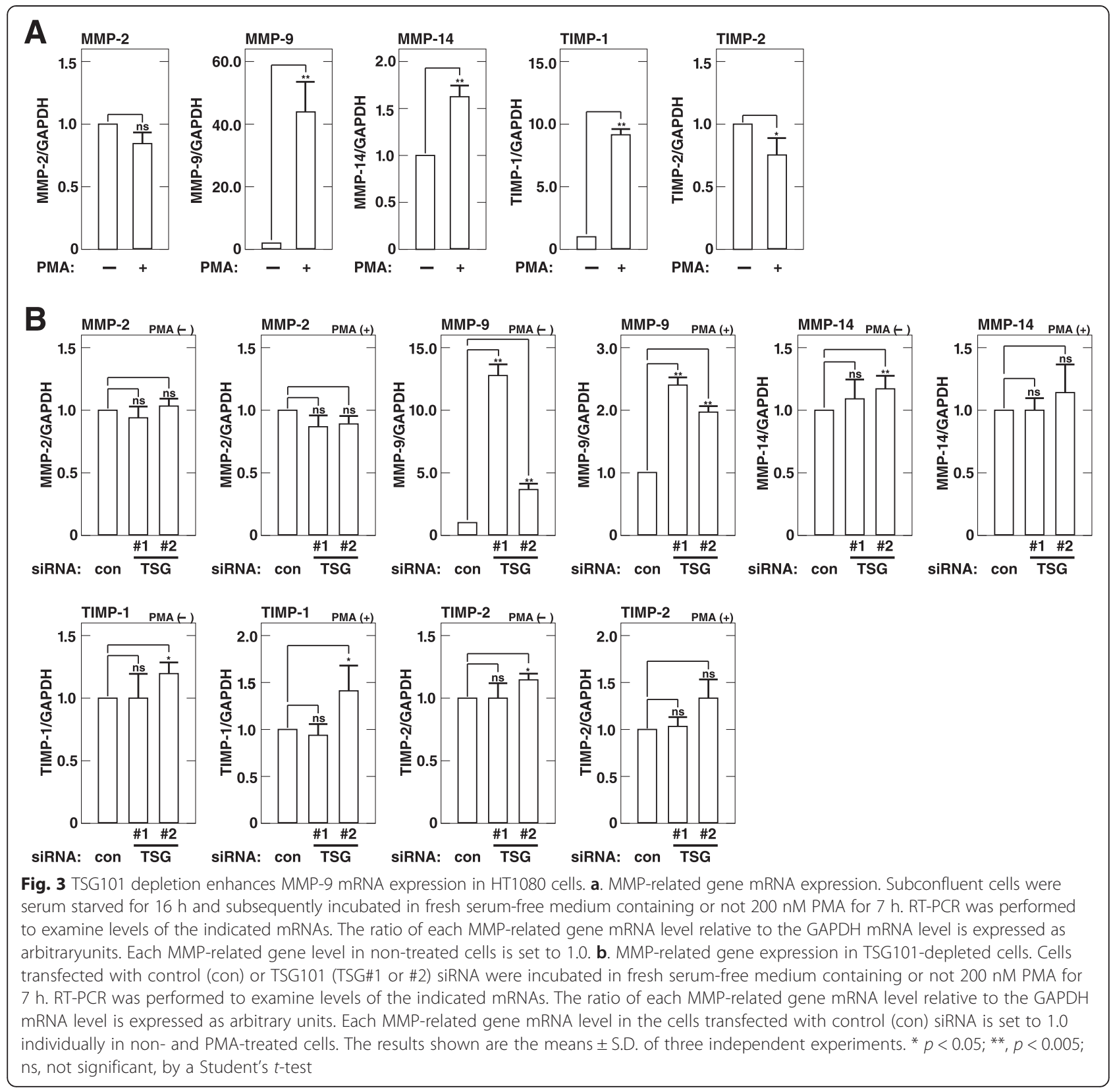

any of these signaling pathways regardless of treatment with PMA.

\section{TSG101 does not affect MMP-9 mRNA stability in HT1080 cells}

Several studies have reported that post-transcriptional mechanisms are involved in the regulation of MMP-9 mRNA levels $[35,36]$. Therefore, to examine the possibility that TSG101 participates in post-transcriptional regulation of MMP-9 mRNA stability, we used an established approach to inhibit new gene transcription and measure MMP-9 mRNA decay over time [48]. There was not a significant difference in level of remaining
MMP-9 or 18S rRNA mRNA at each time point between control and TSG101-depleted cells (Additional file 2: Figure S2A and B), suggesting that TSG101 does not participate in post-transcriptional regulation of MMP-9 mRNA stability in HT1080 cells.

\section{TSG101 modulates cell invasion of HT1080 cells in an MMP-9-dependent manner}

Our results strongly support the possibility that TSG101 is involved in cell invasion of HT1080 cells through regulating MMP-9 expression. To explore this possibility, we first examined whether MMP-9 is involved in cell invasion of HT1080 cells. Western blot analysis confirmed 

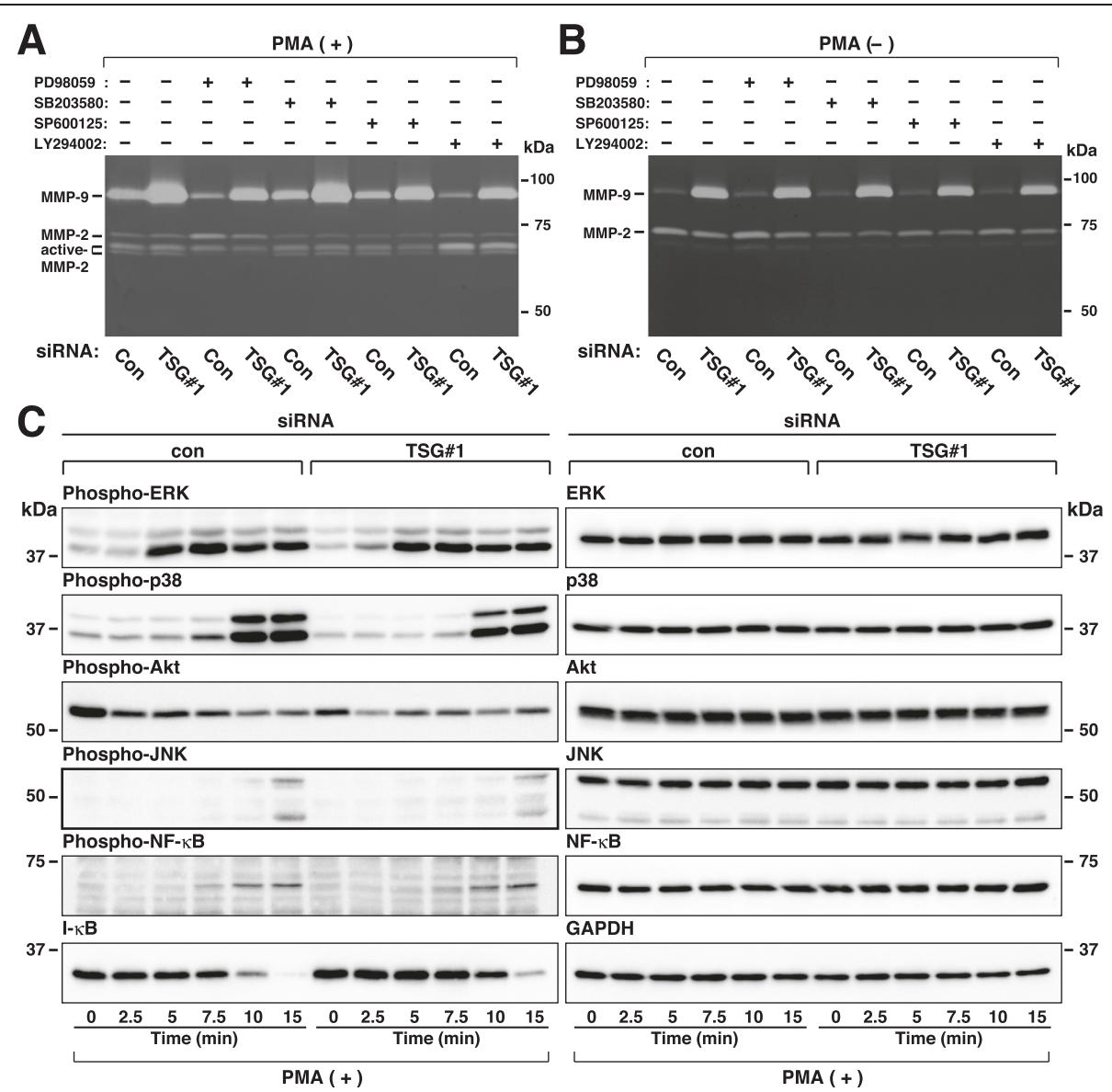

Fig. 4 TSG101 depletion has little impact on the signaling pathways in PMA-stimulated HT1080 cells. Cells transfected with control (con) or TSG101 (TSG\#1) siRNA were incubated in fresh serum-free medium containing the indicated reagents. a-b. Cells were incubated with $50 \mu \mathrm{M}$

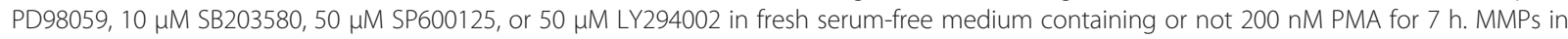
conditioned media from PMA-treated (a) and non-treated (b) cells were measured using gelatin zymography. c. Cells were incubated in fresh serum-free medium containing 200 nM PMA for the indicated periods of time. Cell lysates were analyzed by western blot using the indicated antibodies. The blots and gels shown are representative of three independent experiments

that targeted knockdown of MMP-9 by siRNA led to decreased levels of MMP-9 expression (Fig. 5a). MMP-9 depletion led to decreased levels of MMP-9 secretion regardless of treatment with PMA (Fig. 5b) and moreover led to decreased numbers of migrated cells on the underside of the filter (Fig. 5c. d), suggesting that MMP-9 is at least involved in cell invasion of HT1080 cells. MMP-9 depletion may partially inhibit cell invasion because MMP-2 secretion is more prominent in HT1080 cells than MMP9 secretion. Next we examined the effect of simultaneous depletion of TSG101 and MMP-9 on cell invasion of HT1080 cells. Simultaneous depletion of TSG101 and MMP-9 reduced numbers of migrated cells on the underside of the filter to the levels seen in the cells treated with MMP-9 siRNA duplexes alone (Fig. 5c, d). Taken together with the results that depletion of neither TSG101 nor MMP-9 affected cell growth of HT1080 cells (data not shown), these results demonstrate that TSG101 is at least involved in cell invasion of HT1080 cells in an MMP-9dependent manner.

\section{TSG101 depletion contrarily decreases MMP-9 mRNA expression in PMA-treated HeLaS3 cells}

To explore whether TSG101 depletion has the same effects in other cell lines as in HT1080 cells, we examined the effect of TSG101 depletion on MMP-9 mRNA expression in U2OS osteosarcoma and HeLaS3 cervical carcinoma cells. Western blot analysis confirmed that targeted knockdown of TSG101 in U2OS and HeLaS3 cells by siRNA led to decreased levels of TSG101 expression (Additional file 3: Figure S3A and Fig. 6a). TSG101 depletion exhibited the same effects on MMP-9 secretion, MMP-9 expression, and MMP-9 mRNA expression in U2OS cells (Additional file 3: Figure S3, b-e). However, depletion of TSG101 using TSG\#1 siRNA duplexes contrarily led to decreased levels of MMP-9 

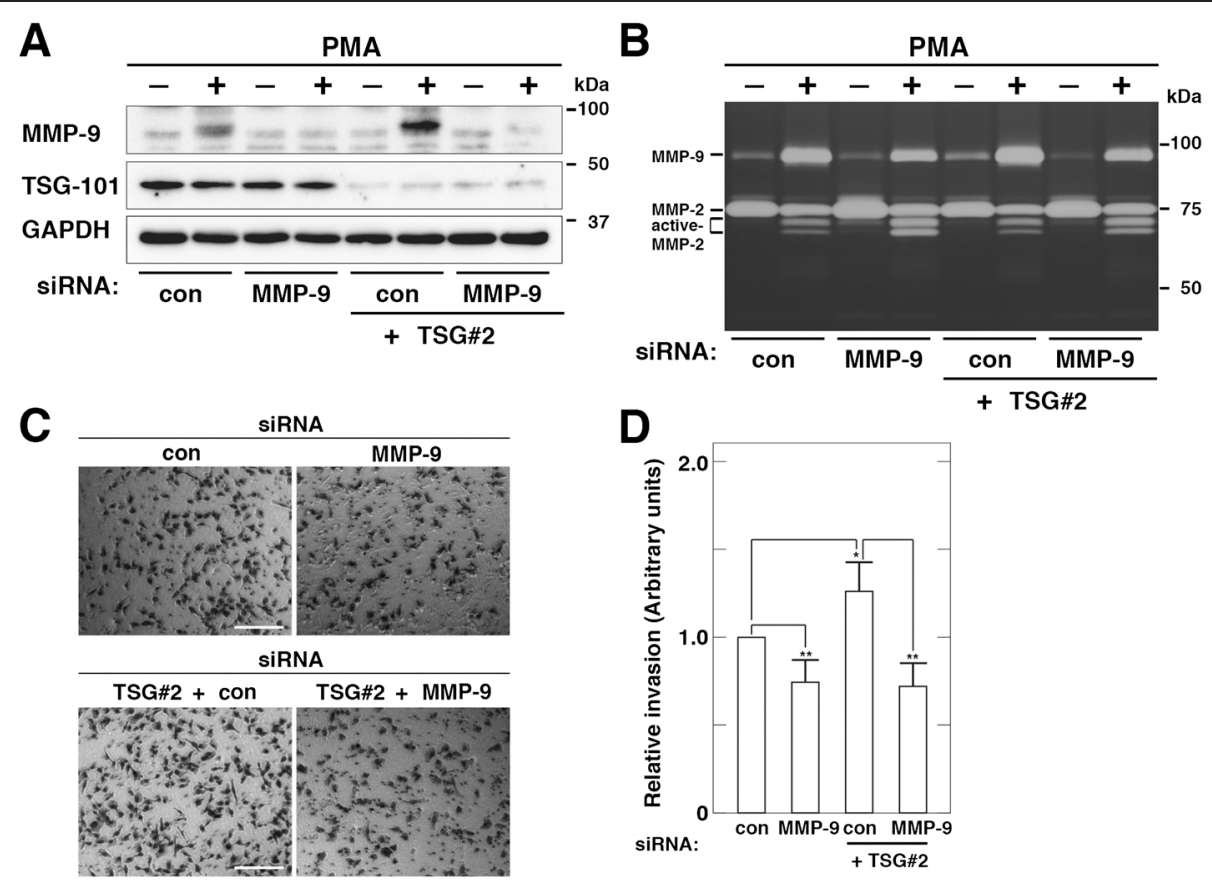

Fig. 5 TSG101 modulates cell invasion of HT1080 cells in an MMP-9-dependent manner. Cells were transfected with control (con) or MMP-9 siRNA to deplete MMP-9, or with TSG101 (TSG\#2) siRNA and control (con) or MMP-9 siRNA to simultaneously deplete TSG101 and MMP-9. a-b. Expression and secretion of MMP-9 in simultaneous TSG101- and MMP-9-depleted cells. Cells were incubated in fresh serum-free medium containing or not 200 nM PMA for $7 \mathrm{~h}$. Cell lysates were analyzed by western blot using the indicated antibodies (a). MMPs in conditioned media were measured using gelatin zymography (b). c-d. Cell invasion of simultaneous TSG101- and MMP-9-depleted cells. Each of the transfected cells was allowed to invade for $18 \mathrm{~h} \mathrm{(c)}$. Scale bars, 200 mm. Cell invasion through the filter in (c) was quantified (d). Relative invasion activities of the cells transfected with MMP-9 siRNA alone, and TSG101 (TSG\#2) siRNA and control (con) or MMP-9 siRNA are expressed as the proportion of infiltration of the cells transfected with control (con) siRNA. The blots, gels, and images shown are representative of three independent experiments. The results shown are the means \pm S.D. of three independent experiments. ${ }^{*} p<0.05 ;{ }^{* *}, p<0.005$; ns, not significant, by a Student's $t$-test

secretion in PMA-treated HeLaS3 cells (Fig. 6b). Moreover, TSG101 depletion using TSG\#1 siRNA duplexes proportionally led to decreased levels of MMP-9 mRNA in PMA-treated HeLaS3 cells (Fig. 6c). Since similar results were obtained using two sets of siRNA duplexes (TSG\#1 and \#2), it is not likely that the decrease in MMP-9 secretion and MMP-9 mRNA expression in PMA-treated cells is due to the off-target effect of siRNA treatment. Moreover, depletion of TSG101 using TSG\#1 siRNA duplexes more effectively led to decreased levels of MMP-9 mRNA than that using TSG\#2 siRNA duplexes, consistent with the results in Fig. 6b showing that depletion of TSG101 using TSG\#1 siRNA duplexes more effectively led to decreased levels of MMP-9 secretion than that using TSG\#2 siRNA duplexes. Together, these results raise the possibility that TSG101 might bidirectionally modulate cell invasion through regulating MMP-9 mRNA expression.

\section{TSG101 depletion reduces cell invasion of HeLaS3 cells}

We next examined whether TSG101 depletion affects cell migration and cell invasion of HeLaS3 cells. Since the effect of TSG101 depletion on MMP-9 secretion in
HeLaS3 cells was observed in the presence of PMA, the following experiments were performed in the presence of PMA. Depletion of TSG101 using TSG\#1 or TSG\#2 siRNA duplexes had no impact on cell migration of PMA-treated HeLaS3 cells (Fig. 6d, e). On the other hand, depletion of TSG101 using TSG\#1 or TSG\#2 siRNA duplexes led to decreased numbers of migrated PMAtreated cells on the underside of the filter (Fig. 6f, g). MMP-9 depletion using MMP-9 siRNA duplexes led to decreased numbers of migrated PMA-treated cells on the underside of the filter (Fig. 6f, g), suggesting that MMP-9 is also involved in cell invasion of HeLaS3 cells. Taken together with the results that depletion of neither TSG101 nor MMP-9 affected cell growth of HeLaS3 cells (data not shown), these results suggest that TSG101 may be implicated in the invasive potency of HeLaS3 cells as a tumorenhancing gene.

TSG101 depletion does not reduce the activities of the signaling pathways required for MMP-9 secretion in HeLaS3 cells

To explore the mechanism underlying decreased levels of PMA-induced MMP-9 mRNA in TSG101-depleted 

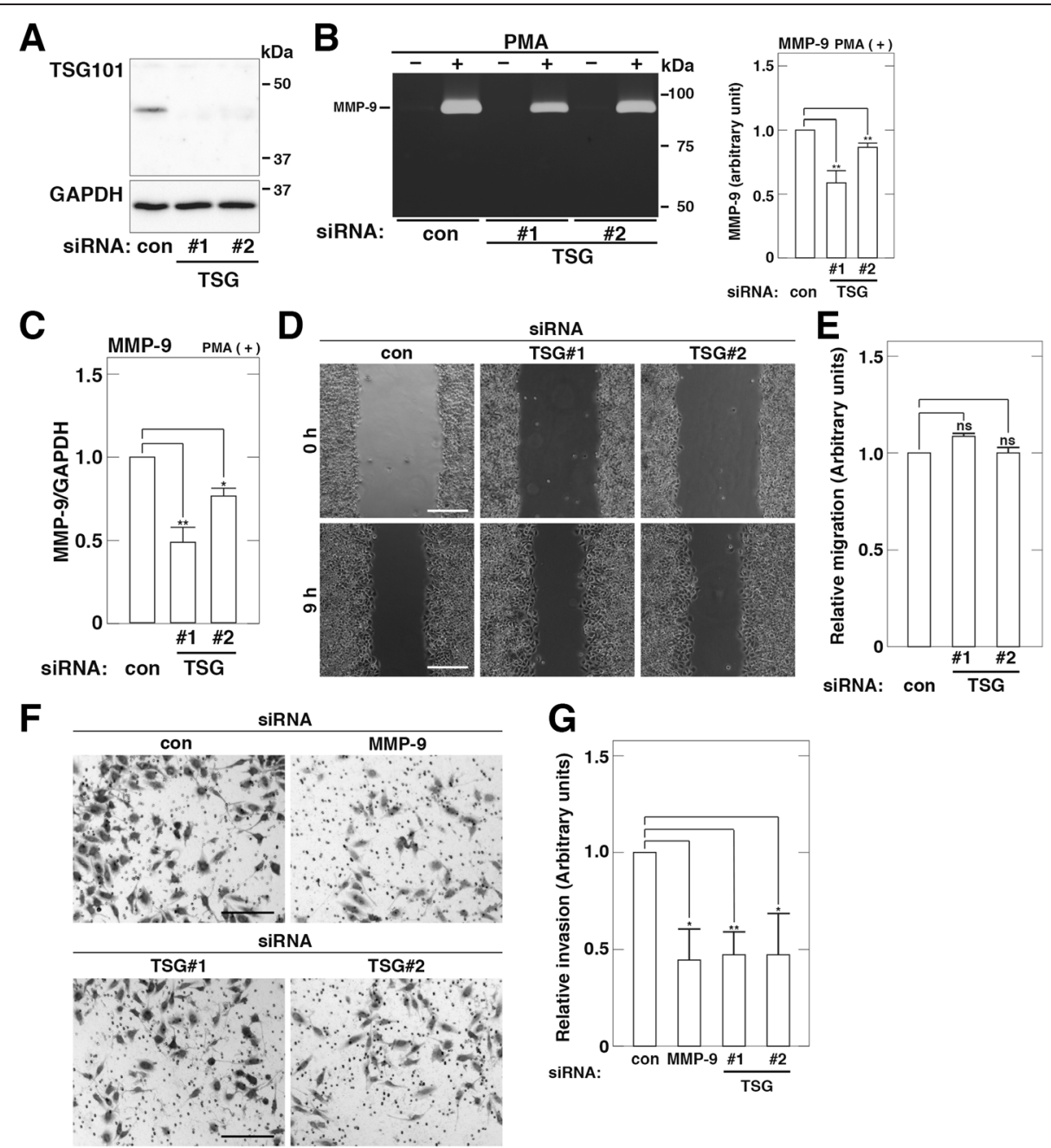

G

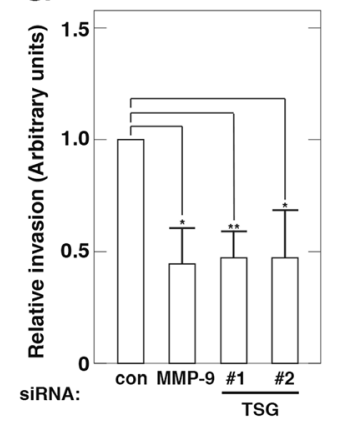

Fig. 6 TSG101 depletion decreases MMP-9 secretion and reduces cell invasion in PMA-treated HeLaS3 cells. Cells were transfected with control (con), TSG101 (TSG\#1 or \#2), or MMP-9 siRNA. a. Depletion of TSG101 by siRNA. Total cell lysates were analyzed by western blot. b-c. MMP-9 secretion and MMP-9 mRNA expression in TSG101-depleted cells. Cells were incubated in fresh serum-free medium containing or not 200 nM PMA for 24 h. MMP9 in conditioned media was measured using gelatin zymography (b, left). The amount of MMP-9 in PMA-treated cells was quantified and is expressed as arbitrary units (b, right). The amount of MMP-9 in conditioned media of the cells transfected with control (con) siRNA is set to 1.0. Expression levels of MMP-9 and GAPDH mRNAs in PMA-treated cells were analyzed by RT-PCR (c). The ratio of MMP-9 mRNA level relative to the GAPDH mRNA level is expressed as arbitrary units. The MMP-9 mRNA level in the cells transfected with control (con) siRNA is set to 1.0. d-e. Cell migration of TSG101-depleted cells. Confluent transfected cells were scratched and incubated in fresh serum-free medium containing $200 \mathrm{nM}$ PMA for $9 \mathrm{~h}$ (d). Scale bars, $200 \mu \mathrm{m}$. Cell migration into the wound area in (d) was quantified (e). Relative migration activities of the cells transfected with TSG101 siRNA are expressed as the proportion of migration of the cells transfected with control (con) siRNA. $\mathbf{f}-\mathbf{g}$. Cell invasion of TSG101-depleted cells. Each of the transfected cells was allowed to invade for $72 \mathrm{~h}$ (f). Scale bars, $200 \mu \mathrm{m}$. Cell invasion through the filter in (f) was quantified (g). Relative invasion activities of the cells transfected with TSG101 or MMP-9 siRNA are expressed as the proportion of infiltration of the cells transfected with control (con) siRNA. The blots, gels, and images shown are representative of three independent experiments. The results shown are the means \pm S.D. of three independent experiments. ${ }^{*} p<0.05 ;{ }^{* *}, p<0.005 ;$ ns, not significant, by a Student's t-test

HeLaS3 cells, we first examined which of the signaling pathways are involved in PMA-induced MMP-9 secretion in HeLaS3 cells. Among various chemical inhibitors, PD98095, SP600125, LY294002, and MG132 significantly reduced PMA-induced MMP-9 secretion while SB203580 had no impact (Fig. 7a), suggesting that the ERK, JNK, PI3-K/Akt, and NF-KB signaling pathways may be at least involved in PMA-induced MMP-9 secretion in HeLaS3 cells. To explore whether TSG101 depletion inhibits PMA-induced activation of these signaling pathways in HeLaS3 cells, we next performed western blotting experiments with phospho-specific antibodies. Although phosphorylated NF- $\mathrm{kB}$ was not detected (data not shown), we speculate that TSG101 depletion did not affect the activation of the NF- $\mathrm{kB}$ pathway because TSG101 depletion did not affect I- $\mathrm{kB}$ degradation 


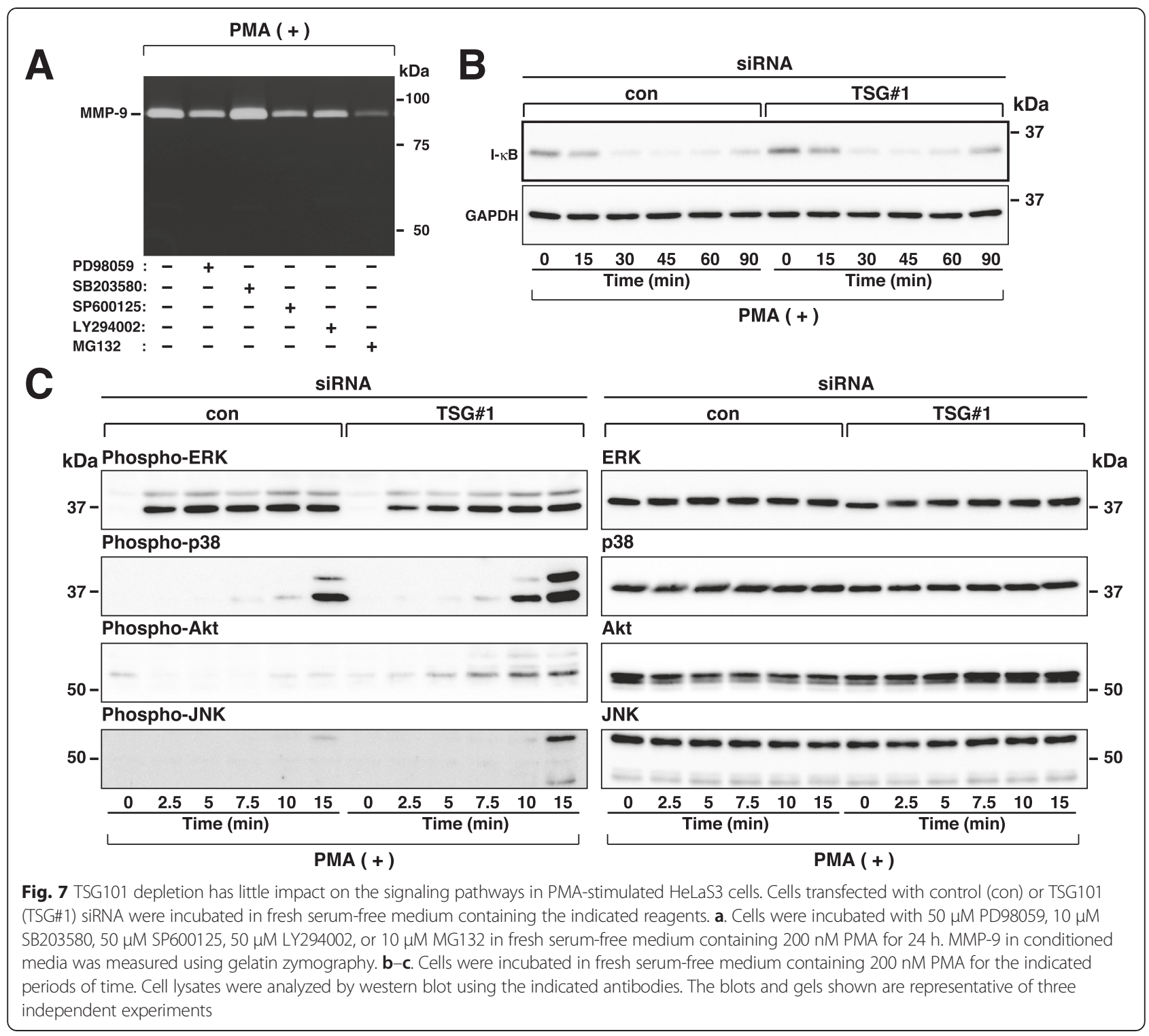

(Fig. 7b). Moreover, TSG101 depletion did not reduce but instead slightly enhanced activations of the p38 kinase, PI3-K/Akt, and JNK signaling pathways (Fig. 7c). Although the precise reason why TSG101 depletion promoted activation of these signaling pathways is not known, it is possible that these signaling pathways may be activated in a compensatory manner. These results suggest that TSG101 depletion does not decrease MMP-9 secretion at least through reducing any of these signaling pathways in PMA-treated HeLaS3 cells.

\section{TSG101 does not affect MMP-9 mRNA stability in} HeLaS3 cells

To investigate whether TSG101 participates in posttranscriptional regulation of MMP-9 mRNA stability in HeLaS3 cells, we measured MMP-9 mRNA decay over time in HeLaS3 cells. However, because of the very low baseline levels of MMP-9 mRNA in HeLaS3 cells, it was necessary to first induce MMP-9 mRNA to detectable levels in these cells so that we could monitor the rate of mRNA turnover. There was not a significant difference in level of remaining MMP-9 or 18S rRNA mRNA at each time point between control and TSG101-depleted cells (Additional file 2: Figure S2C and D), suggesting that TSG101 does not participate in post-transcriptional regulation of MMP-9 mRNA stability in HeLaS3 cells.

\section{Discussion}

In tumor invasion, degradation of ECM proteins by tumor cells disrupts this structure, enabling tumor cell invasion through the matrix [49]. The ability of tumor cells to invade into and migrate through their 
surrounding environment is directly correlated with the morbidity and mortality of all forms of cancer. Therefore, the mechanism of the degradation of ECM proteins by tumor cells has been intensively studied and evidence is emerging showing that MMPs play a central role in ECM degradation and cellular invasion [23-26]. Among the MMPs, MMP-9 is thought to play a pivotal role in the degradation of basement membrane collagen IV and therefore may mainly contribute to the invasive ability of various types of tumor cells [27-30]. Consistently, MMP9 depletion reduced cell invasion of HT1080 and HeLaS3 cells, indicating a role for MMP-9 in cell invasion. On the basis of our present finding that TSG101 depletion promoted cell invasion and MMP-9 expression in HT1080 cells, but contrarily reduced these events in HeLaS3 cells, TSG101 may be implicated in the invasive potency of tumor cells through regulating the expression of MMP-9. As expected, the enhancement of cell invasion by TSG101 depletion was attenuated by simultaneous depletion of MMP-9 in HT1080 cells. Together, these data suggested that TSG101 participates in cell invasion in an MMP-9dependent manner.

The expression and secretion of MMP-9 is regulated at several levels: transcription, mRNA stability, translation, protein degradation, and protein secretion [35-37]. We found that TSG101 depletion increased the levels of MMP-9 mRNA in HT1080 and U2OS cells, but contrarily decreased the levels of MMP-9 mRNA in HeLaS3 cells, and we also found that TSG101 depletion did not affect MMP-9 mRNA stability in either HT1080 or HeLaS3 cells. We did not explore the effect of TSG101 depletion on MMP-9 translation. However, since changes in MMP9 protein levels were proportional to those in MMP-9 mRNA levels in TSG101-depleted cells, we speculate that TSG101 depletion does not affect this step. Together, our present results suggest that TSG101 might bidirectionally modulate the transcription of MMP-9 gene in different cell types.

The promoter of the human MMP-9 gene contains multiple functional cis-regulatory elements including AP-1, NF-kB, Sp-1, Ets-1, and Egr-1 elements, which are involved in baseline and induced transcriptional responses $[43,46,50]$. Several studies have shown that the transcription of MMP-9 is activated by several signaling pathways via these elements $[40,42,50]$. On the basis of our present finding that TSG101 depletion had little impact on any signaling pathways involved in PMAinduced MMP-9 secretion, it is not likely that TSG101 modulates the activities of the signaling pathways required for MMP-9 secretion. We have not yet elucidated the precise mechanism by which TSG101 participates in regulation of the transcription of MMP-9. However, TSG101 may directly or indirectly modulate the transcription of MMP-9 in the nucleus, based on the following observations. Previous reports showed that TSG101 acts as a transcriptional modulator to affect nuclear hormone receptor-mediated transcriptional activation $[6,9]$ and demonstrated that TSG101 interacts with and downregulates the promoter of p21, a tumor suppressor gene [7]. In synchronized cell lines, TSG101 is present in both the nucleus and Golgi complex during interphase, dispersed more generally throughout the cytoplasm in late S phase, and enriched in mitotic spindles and centrosomes during mitosis [15], implying that TSG101 plays diverse roles in both nucleus and cytoplasm.

The functions of TSG101 in carcinogenesis and tumor progression have been controversial. Besides cell invasion, we found that TSG101 depletion did not affect cell growth or cell migration of HT1080 or HeLaS3 cells, although it was reported that TSG101 depletion inhibits cell growth and cell migration of prostate cancer PC3, breast cancer MDA-MB-231, and breast cancer MCF-7 cells $[19,20]$. We were unable to clarify the reason why TSG 101 depletion had no impact on cell growth or cell migration of HT1080 or HeLaS3 cells, but expect that the unprecedented link between TSG101 function and MMP-9 mRNA expression provides a clue to reveal the mechanism underlying the controversial functions of TSG101 in carcinogenesis and tumor progression. Further studies to unravel the precise mechanism by which TSG101 bidirectionally modulates the transcription of MMP-9 are necessary. Furthermore, we conceive that there may be a difference in pathological roles of TSG101 between tumor cell types derived from epithelial and mesenchymal tissues. TSG101 was originally identified as a tumor suppressor gene in mouse fibroblasts. HT1080 and U2OS cells, of which TSG101 depletion promoted cell invasion and increased MMP-9 expression, are derived from mesenchymal tissues. On the other hand, HeLaS3 cells, of which TSG101 depletion reduced cell invasion and decreased MMP-9 expression, are derived from epithelial tissues. PC3, MDA-MB-231, and MCF-7 cells, where TSG101 has been reported to function as a tumorenhancing gene, are derived from epithelial tissues. Moreover, it has been recently reported that positive TSG101 expression is significantly associated with invasion of adenocarcinoma of the gallbladder [51]. Although further studies are necessary, TSG101 may play pathological roles as a tumor-enhancing gene in tumor cell types derived from epithelial tissues.

\section{Conclusion}

In summary, we found that TSG101 bidirectionally modulated cell invasion through regulating MMP-9 mRNA expression in different cell types. TSG101, which was initially identified as a tumor suppressor gene, is also known to contrarily function as a tumor-enhancing gene 
[1]. To the best of our knowledge, our present findings are the first report providing a new insight into a putative mechanism by which TSG101 bidirectionally participates in carcinogenesis and tumor progression as a multifaceted gene in different cell types.

\section{Additional files}

Additional file 1: Figure S1. TSG101 depletion does not affect MMP-9 degradation in HT1080 cells. Cells transfected with control (con) or TSG101 (TSG\#1) siRNA were incubated with $10 \mu \mathrm{M}$ MG132 or $100 \mathrm{nM}$ bafilomycin A1 (BafA1) in fresh serum-free medium containing or not 200 nM PMA for $7 \mathrm{~h}$. MMPs in conditioned media $(\mathbf{A})$ and cell lysates $(\mathbf{B})$ were measured using gelatin zymography. The gels shown are representative of three independent experiments. (PDF $1033 \mathrm{~kb}$ )

Additional file 2: Figure S2. TSG101 depletion does not affect MMP-9 mRNA stability in either HT1080 or HeLaS3 cells. Stability of MMP-9 mRNA in TSG101-depleted HT1080 cells (A and B) and TSG101-depleted HeLaS3 cells (C and D). Cells transfected with control or TSG101 (TSG\#1) siRNA were incubated in fresh serum-free medium containing $1 \mathrm{\mu g} / \mathrm{ml}$ actinomycin D for various time points and RT-PCR was performed to monitor turnover of MMP-9 mRNA. Expression levels of MMP-9 (A and C) and 18S rRNA (B and D) mRNAs were analyzed by RT-PCR. Results are plotted as the percentage of mRNA remaining relative to the starting amounts at $0 \mathrm{~h}$ individually in control and TSG101 (TSG\#1) siRNA transfected cells. The results shown are the means \pm S.D. of three independent experiments. Ns, not significant, by Student's t-test. (PDF $351 \mathrm{~kb}$ )

Additional file 3: Figure S3. TSG101 depletion leads to increased levels of MMP-9 mRNA in U2OS cells. (A) Depletion of TSG101 by siRNA. Total cell lysates of cells transfected with control (con) or TSG101 (TSG\#1) siRNA were analyzed by western blot using the indicated antibodies. (B) and (C) Secretion and expression of MMP-9 in TSG101-depleted cells. Cells transfected with control (con) or TSG101 (TSG\#1) siRNA were incubated in fresh serum-free medium containing or not $200 \mathrm{nM}$ PMA for $7 \mathrm{~h}$. MMPs in conditioned media (B) and cell lysates (C) were measured using gelatin zymography. (D) MMP-9 mRNA expression in PMA-treated cells. Subconfluent cells were serum starved for $16 \mathrm{~h}$ and subsequently incubated in fresh serum-free medium containing or not 200 nM PMA for $7 \mathrm{~h}$. Expression levels of MMP-9 and GAPDH mRNAs were analyzed by RT-PCR. The ratio of MMP-9 mRNA level relative to the GAPDH mRNA level is expressed as arbitrary units. MMP-9 mRNA level in non-treated cells is set to 1.0. (E) MMP-9 mRNA expression in TSG101-depleted cells. Cells transfected with control (con) or TSG101 (TSG\#1) siRNA were incubated in fresh serum-free medium containing or not $200 \mathrm{nM}$ PMA for $7 \mathrm{~h}$. The ratio of MMP-9 mRNA level relative to the GAPDH mRNA level is expressed as arbitrary units. MMP-9 mRNA level in the cells transfected with control (con) siRNA is set to 1.0 individually in non- and PMA-treated cells. The blots and gels shown are representative of three independent experiments. The results shown are means \pm S.D. of three independent experiments. ${ }^{* *}$, $p<0.005$, by a Student's t-test. (PDF $592 \mathrm{~kb}$ )

\section{Abbreviations}

TSG101: Tumor susceptibility gene 101; MMPs: Matrix metalloproteinases; ECM: Extracellular matrix; TIMP: Tissue inhibitors of metalloproteinases; RNAi: RNA interference; FCS: Fetal calf serum; GAPDH: Glyceraldehyde-3phosphate dehydrogenase; siRNA: Small interfering RNA; PBS: Phosphate buffered saline; PMA: Phorbol 12-myristate 13-acetate; BSA: Bovine serum albumin; RT: Reverse transcription.

\section{Competing interests}

The authors declare that they have no competing interests.

\section{Authors' contributions}

XBS, TM, and Hiromichi S performed the bulk part of the experiments and analyzed the results. YH gave technical support for the gelatin zymography Hiroshi S performed the statistical analysis. $\mathrm{HH}$ and Hiromichi S participated in the design of the study and supervised all the experiments. All authors discussed the results and actively contributed to the manuscript. All authors read and approved the final manuscript.

\section{Acknowledgments}

This work was supported by a Grants-in-Aid for scientific research from the Ministry of Education, Culture, Sports, Science and Technology, Japan (2013). We thank Mayumi Ohshima and Akemi Akima for their skillful assistance.

\section{Author details}

'Department of Molecular and Cell Biology, Graduate School of Medicine, Dokkyo Medical University, 880 Kitakobayashi, Mibu-cho, Tochigi 321-0293, Japan. ${ }^{2}$ Department of Gastroenterology, Graduate School of Medicine, Dokkyo Medical University, 880 Kitakobayashi, Mibu-cho, Tochigi 321-0293, Japan. ${ }^{3}$ Present Address: Laboratory of Immunobiology, Faculty of Pharmaceutical Sciences, Fukuyama University, Sanzo Ichibanchi, Gakuencho, Fukuyama, Hiroshima 729-0292, Japan.

Received: 12 August 2015 Accepted: 19 November 2015 Published online: 25 November 2015

\section{References}

1. Li L, Cohen SN. Tsg101: a novel tumor susceptibility gene isolated by controlled homozygous functional knockout of allelic loci in mammalian cells. Cell. 1996:85:319-29.

2. Li L, Liao J, Ruland J, Mak TW, Cohen SN. A TSG101/MDM2 regulatory loop modulates MDM2 degradation and MDM2/p53 feedback control. Proc Natl Acad Sci U S A. 2001;98:1619-24.

3. Babst M, Odorizzi G, Estepa EJ, Emr SD. Mammalian tumor susceptibility gene 101 (TSG101) and the yeast homologue, Vps23p, both function in late endosomal trafficking. Traffic. 2000;1:248-58.

4. Razi M, Futter CE. Distinct roles for Tsg101 and Hrs in multivesicular body formation and inward vesiculation. Mol Biol Cell. 2006;17:3469-83.

5. Rush JS, Ceresa BP. RAB7 and TSG101 are required for the constitutive recycling of unliganded EGFRs via distinct mechanisms. Mol Cell Endocrinol. 2013;381:188-97.

6. Hittelman AB, Burakov D, Iniguez-Lluhi JA, Freedman LP, Garabedian MJ. Differential regulation of glucocorticoid receptor transcriptional activation via AF-1-associated proteins. EMBO J. 1999;18:5380-8.

7. Lin YS, Chen YJ, Cohen SN, Cheng TH. Identification of TSG101 functional domains and p21 loci required for TSG101-mediated p21 gene regulation. PLoS One. 2013;8, e79674.

8. Rountree MR, Bachman KE, Baylin SB. DNMT1 binds HDAC2 and a new co-repressor, DMAP1, to form a complex at replication foci. Nat Genet. 2000;25:269-77.

9. Sun Z, Pan J, Hope WX, Cohen SN, Balk SP. Tumor susceptibility gene 101 protein represses androgen receptor transactivation and interacts with p300. Cancer. 1999:86:689-96.

10. Watanabe M, Yanagi Y, Masuhiro Y, Yano T, Yoshikawa H, Yanagisawa J, et al. A putative tumor suppressor, TSG101, acts as a transcriptional suppressor through its coiled-coil domain. Biochem Biophys Res Commun. 1998;245:900-5.

11. Wagner KU, Krempler A, Qi Y, Park K, Henry MD, Triplett AA, et al. Tsg101 is essential for cell growth, proliferation, and cell survival of embryonic and adult tissues. Mol Cell Biol. 2003;23:150-62.

12. Lobert VH, Stenmark H. Cell polarity and migration: emerging role for the endosomal sorting machinery. Physiology (Bethesda). 2011;26:171-80.

13. Stuffers $S$, Brech A, Stenmark H. ESCRT proteins in physiology and disease. Exp Cell Res. 2009;315:1619-26.

14. Stuffers S, Sem Wegner C, Stenmark H, Brech A. Multivesicular endosome biogenesis in the absence of ESCRTs. Traffic. 2009;10:925-37.

15. Xie W, Li L, Cohen SN. Cell cycle-dependent subcellular localization of the TSG101 protein and mitotic and nuclear abnormalities associated with TSG101 deficiency. Proc Natl Acad Sci U S A. 1998;95(4):1595-600.

16. Zhong $Q$, Chen $Y$, Jones $D$, Lee $W H$. Perturbation of TSG101 protein affects cell cycle progression. Cancer Res. 1998;58:2699-702.

17. Baldys A, Raymond JR. Critical role of ESCRT machinery in EGFR recycling Biochemistry. 2009:48:9321-3.

18. Lu Q, Hope LW, Brasch M, Reinhard C, Cohen SN. TSG101 interaction with HRS mediates endosomal trafficking and receptor down-regulation. Proc Natl Acad Sci U S A. 2003;100:7626-31. 
19. Zhang Y, Song M, Cui ZS, Li CY, Xue XX, Yu M, et al. Down-regulation of TSG101 by small interfering RNA inhibits the proliferation of breast cancer cells through the MAPK/ERK signal pathway. Histol Histopathol. 2011;26:87-94.

20. Zhu G, Gilchrist R, Borley N, Chng HW, Morgan M, Marshall JF, et al. Reduction of TSG101 protein has a negative impact on tumor cell growth. Int J Cancer. 2004;109:541-7.

21. Brinckerhoff CE, Matrisian LM. Matrix metalloproteinases: a tail of a frog that became a prince. Nat Rev Mol Cell Biol. 2002;3:207-14.

22. Chakraborti S, Mandal M, Das S, Mandal A, Chakraborti T. Regulation of matrix metalloproteinases: an overview. Mol Cell Biochem. 2003;253: 269-85.

23. Egeblad M, Werb Z. New functions for the matrix metalloproteinases in cancer progression. Nat Rev Cancer. 2002;2:161-74.

24. Johnson LL, Dyer R, Hupe DJ. Matrix metalloproteinases. Curr Opin Chem Biol. 1998;2:466-71.

25. Liotta LA, Tryggvason K, Garbisa S, Hart I, Foltz CM, Shafie S. Metastatic potential correlates with enzymatic degradation of basement membrane collagen. Nature. 1980;284:67-8.

26. Stamenkovic I. Matrix metalloproteinases in tumor invasion and metastasis. Semin Cancer Biol. 2000;10:415-33.

27. Hua J, Muschel RJ. Inhibition of matrix metalloproteinase 9 expression by a ribozyme blocks metastasis in a rat sarcoma model system. Cancer Res. 1996;56:5279-84.

28. Sehgal G, Hua J, Bernhard EJ, Sehgal I, Thompson TC, Muschel RJ. Requirement for matrix metalloproteinase-9 (gelatinase B) expression in metastasis by murine prostate carcinoma. Am J Pathol. 1998;152:591-6.

29. Montgomery AM, Mueller BM, Reisfeld RA, Taylor SM, DeClerck YA. Effect of tissue inhibitor of the matrix metalloproteinases-2 expression on the growth and spontaneous metastasis of a human melanoma cell line. Cancer Res. 1994;54:5467-73.

30. Sugiura $Y$, Shimada $H$, Seeger RC, Laug WE, DeClerck YA. Matrix metalloproteinases-2 and -9 are expressed in human neuroblastoma: contribution of stromal cells to their production and correlation with metastasis. Cancer Res. 1998:58:2209-16.

31. Roomi MW, Monterrey JC, Kalinovsky T, Niedzwiecki A, Rath M. Modulation of MMP-2 and MMP-9 by cytokines, mitogens and inhibitors in lung cancer and malignant mesothelioma cell lines. Oncol Rep. 2009;22:1283-91.

32. Roomi MW, Monterrey JC, Kalinovsky T, Rath M, Niedzwiecki A. In vitro modulation of MMP-2 and MMP-9 in human cervical and ovarian cancer cell lines by cytokines, inducers and inhibitors. Oncol Rep. 2010;23:605-14.

33. Kajanne R, Miettinen P, Mehlem A, Leivonen SK, Birrer M, Foschi M, et al. EGF-R regulates MMP function in fibroblasts through MAPK and AP-1 pathways. J Cell Physiol. 2007;212:489-97.

34. Leber TM, Balkwill FR. Regulation of monocyte MMP-9 production by TNF-alpha and a tumour-derived soluble factor (MMPSF). Br J Cancer. 1998;78:724-32.

35. Iyer V, Pumiglia K, DiPersio CM. Alpha3beta1 integrin regulates MMP-9 mRNA stability in immortalized keratinocytes: a novel mechanism of integrin-mediated MMP gene expression. J Cell Sci. 2005;118:1185-95.

36. Jiang Y, Muschel RJ. Regulation of matrix metalloproteinase-9 (MMP-9) by translational efficiency in murine prostate carcinoma cells. Cancer Res. 2002;62:1910-4.

37. Westermarck J, Kahari VM. Regulation of matrix metalloproteinase expression in tumor invasion. FASEB J. 1999:13:781-92.

38. Gum R, Wang H, Lengyel E, Juarez J, Boyd D. Regulation of $92 \mathrm{kDa}$ type IV collagenase expression by the jun aminoterminal kinase- and the extracellular signal-regulated kinase-dependent signaling cascades. Oncogene. 1997;14: 1481-93.

39. Huhtala P, Tuuttila A, Chow LT, Lohi J, Keski-Oja J, Tryggvason K. Complete structure of the human gene for $92-\mathrm{kDa}$ type IV collagenase. Divergent regulation of expression for the 92- and 72-kilodalton enzyme genes in HT-1080 cells. J Biol Chem. 1991;266:16485-90.

40. Kim D, Kim S, Koh H, Yoon SO, Chung AS, Cho KS, et al. Akt/PKB promotes cancer cell invasion via increased motility and metalloproteinase production. FASEB J. 2001;15:1953-62.

41. Moll UM, Youngleib GL, Rosinski KB, Quigley JP. Tumor promoter-stimulated Mr 92,000 gelatinase secreted by normal and malignant human cells: isolation and characterization of the enzyme from HT1080 tumor cells. Cancer Res. 1990;50:6162-70.

42. Park SY, Kim JH, Lee YJ, Lee SJ, Kim Y. Surfactin suppresses TPA-induced breast cancer cell invasion through the inhibition of MMP-9 expression. Int J Oncol. 2013;42:287-96.
43. Sato $\mathrm{H}$, Seiki M. Regulatory mechanism of $92 \mathrm{kDa}$ type IV collagenase gene expression which is associated with invasiveness of tumor cells. Oncogene. 1993;8:395-405.

44. Simon C, Goepfert H, Boyd D. Inhibition of the p38 mitogen-activated protein kinase by SB 203580 blocks PMA-induced Mr 92,000 type IV collagenase secretion and in vitro invasion. Cancer Res. 1998;58:1135-9.

45. Simon C, Hicks MJ, Nemechek AJ, Mehta R, O'Malley Jr BW, Goepfert H, et al. PD 098059, an inhibitor of ERK1 activation, attenuates the in vivo invasiveness of head and neck squamous cell carcinoma. Br J Cancer. 1999;80:1412-9.

46. Van den Steen PE, Dubois B, Nelissen I, Rudd PM, Dwek RA, Opdenakker G. Biochemistry and molecular biology of gelatinase $B$ or matrix metalloproteinase-9 (MMP-9). Crit Rev Biochem Mol Biol. 2002;37:375-536.

47. Surjit M, Varshney B, Lal SK. The ORF2 glycoprotein of hepatitis E virus inhibits cellular NF-kappaB activity by blocking ubiquitination mediated proteasomal degradation of IkappaBalpha in human hepatoma cells. BMC Biochem. 2012;13:7.

48. Huang ZF, Massey JB, Via DP. Differential regulation of cyclooxygenase-2 (COX-2) mRNA stability by interleukin-1 beta (IL-1 beta) and tumor necrosis factor-alpha (TNF-alpha) in human in vitro differentiated macrophages. Biochem Pharmacol. 2000;59:187-94.

49. Stetler-Stevenson WG. The role of matrix metalloproteinases in tumor invasion, metastasis, and angiogenesis. Surg Oncol Clin N Am. 2001;10: 383-92. $x$.

50. Shin SY, Kim JH, Baker A, Lim Y, Lee YH. Transcription factor Egr-1 is essential for maximal matrix metalloproteinase- 9 transcription by tumor necrosis factor alpha. Mol Cancer Res. 2010;8:507-19.

51. Liu Z, Yang Z, Liu D, Li D, Zou Q, Yuan Y, et al. TSG101 and PEG10 are prognostic markers in squamous cell/adenosquamous carcinomas and adenocarcinoma of the gallbladder. Oncol Lett. 2014;7:1128-38.

\section{Submit your next manuscript to BioMed Central and we will help you at every step:}

- We accept pre-submission inquiries

- Our selector tool helps you to find the most relevant journal

- We provide round the clock customer support

- Convenient online submission

- Thorough peer review

- Inclusion in PubMed and all major indexing services

- Maximum visibility for your research

Submit your manuscript at www.biomedcentral.com/submit 